\title{
Hemp seed cake increases fatty acids but does not transfer cannabinoids in eggs and tissues of laying hens
}

\author{
Rajasekhar Kasula ${ }^{1}$, Fausto Solis ${ }^{1 *}$, Byron Shaffer ${ }^{2}$, Frank Connett ${ }^{2}$, Chris Barrett ${ }^{2}$, \\ Rodney Cocker ${ }^{2}$ and Eric Willinghan ${ }^{3}$
}

\footnotetext{
${ }^{1}$ Wenger Animal Nutrient and Technology Innovation Center, the Wenger Group, 101 West Harrisburg Avenue, Rheems, PA 17570, USA.

${ }^{2}$ Kreider Farms, 1145 Colebrook Rd, Mount Joy, PA 17552, USA.

${ }^{3}$ Winfield Veterinary Consulting, Inc., Lake Worth, Florida, USA, 10119 Berlin-Mitte, Germany.
}

Received 13 November, 2020; Accepted 26 May, 2021

\begin{abstract}
Hemp seed and hemp seed products such as hemp seed cake (HSC) have been shown to increase unsaturated fatty acid (FA) profile in eggs, including linoleic acid, and $\alpha$-linolenic fatty acids known to increase egg weight and better human health respectively. However, the use of hemp products in animal feed is still a concern due to the potential residues of the $\Delta-9$ tetrahydrocannabinol (THC), a psychoactive substance present in the hemp plant. No significant published research is available on the effect of dietary HSC on fatty acids profile and cannabinoids residues in organs and tissues of laying hens. The objectives of this study were to determine the effect of dietary HSC on the level of fatty acids composition, and cannabinoid transfer in eggs, as well as internal organs and tissues of laying hens. Eight hundred caged Bovans white hens in at $\mathbf{3 0}$ weeks of age were distributed into 4 treatments of 200 hens per treatment based on inclusion levels of hemp seed cake (HSC) at 0, 10, 20 and $30 \%$ levels of inclusion. Each treatment group comprised of 8 cages of 25 hens each that served as replicates. The observations per protocol were made over a timeline of 16 weeks following that precedes a 3-week acclimation phase. HSC feeding to commercial laying hens increased $(P<0.05)$ the levels of polyunsaturated fatty acids including linoleic and linolenic acids in eggs and abdominal fat. The cannabinoids residues in eggs, blood, breast meat, body fat, liver, kidneys and spleen were below the detectable level. The results of this study confirm that HSC fed to laying hens increased deposition of polyunsaturated fatty acids, but did not contribute THC or cannabinoid residues in eggs, internal organs or body tissues.
\end{abstract}

Key words: Hemp, hemp seed cake (HSC), eggs, tetrahydrocannabinol (THC), fatty acids, cannabinoids

\section{INTRODUCTION}

Hemp (Cannabis sativa L.) is an annual herbaceous plant belonging to the family Cannabinaceae (Turner et al., 1979), traditionally grown for fiber and seed production. Whole hemp seed contains approximately $25 \%$ crude protein, 33 to $35 \%$ oil, and $34 \%$ carbohydrate, in addition to a broad range of vitamins and minerals (Darshan and Rudolph, 2000; Callaway, 2004; House et al., 2010). Hemp seed oil contains 75 to $80 \%$ polyunsaturated fatty 
acids (PUFA), including $60 \%$ linoleic acid and 17 to $19 \%$ a-linolenic acid (ALA) (Parker et al., 2003). The nutrient composition of hemp products provides evidence that these products may serve as potentially valuable livestock feed ingredients.

In the past, the cultivation of hemp was prohibited due to the high content of $\Delta-9$ tetrahydrocannabinol, a psychoactive substance present in the hemp plant. In the recent decades, regulatory changes undertaken by several countries across the globe allowed for the legal cultivation of industry hemp under a license that permits plants and plant parts of the genera Cannabis, the leaves and flowering heads of which do not contain more than $0.3 \% \Delta-9$ tetrahydrocannabinol (wt/wt), and includes the derivatives of such plants and plant parts (Health Canada, 2012; Jing et al., 2017). The nutritional profile, in addition to the increase in production and availability of hemp and hemp products create opportunities to use them in livestock diets (Gakhar et al., 2012). Significant research across the globe that has gone into evaluating the safety of the ingredient showed that including hemp in animal feed is safe and offers benefits for improved animal performance and human health (Gakhar et al., 2012; Jing et al., 2017). Hemp and hemp products in layers not only contribute protein but also they can be valuable sources of essential fatty acids such as linoleic acid to improve egg weight (March and MacMillan, 1990; Parker et al., 2003; Silversides and LeFrancois, 2005) and linolenic acid, an omega 3 fatty acids, which have proven to have beneficial effects on human health (Erasmus, 1993; Lewis et al., 2000).

It has been demonstrated that the addition of ingredients contributing fatty acids in the feed contribute with the fatty acid deposition in animal tissues such as meat and eggs (Gonzalez-Esquerra and Leeson, 2001; Ribeiro et al., 2014; Jing et al., 2017). This can be considered a significant accomplishment for fulfilling current recommendations of increasing n-3 fatty acid intakes, particularly in most western countries where the recommended daily intake of these compounds is rarely met (Kris-Etherton et al., 2000, 2003).

The polyunsaturated fatty acids (PUFA) composition of cell membranes is to a great extent dependent on the dietary intake (Simopoulos, 2002). When people ingest EPA and DHA from the diet, they partially replace the omega- 6 fatty acids, especially arachidonic acid, in the membranes of probably all cells, but especially in the membranes of platelets, erythrocytes, neutrophils, monocytes and liver cells (Simopoulos, 1994). Very high level of omega-6 similar to the food in Western hemisphere diets (Weber, 1989; Weber and Leaf, 1991), products such as prostaglandins, thromboxanes, leukotrienes, hydroxy fatty acids and lipoxins are formed in large quantities which may contribute to the formation of thrombus, and atheroma, to allergy and inflammatory disorders (Simopoulos, 2002). Since a diet high in omega 6 shift the physiological state to one that is prothrombotic, there is an increase in blood viscosity, vasospasm, and vasoconstriction and decreases in bleeding time. Hemp has shown in previous studies to reduce the omega 6/omega 3 fatty acid ratios which contribute to enhanced human health (Simopoulos, 1994).

Hemp products are also shown to be excellent sources of yolk pigmentation, lutein and fatty acid enrichment of eggs. Genetic improvements to limit $\Delta-9$ tetrahydrocannabinol to less than $0.3 \%(\mathrm{w} / \mathrm{w})$ in hemp leaves and flowering heads of the genera Cannabis, have made them safer as a feed ingredient. The use of hemp seed cake (HSC) has not been approved in diets for any class of livestock in the USA due to a lack of research in support of its safety and efficacy (Malone and Gomez, 2018). The current study is designed to determine the effects of feeding HSC on the fatty acids profile and cannabinoid residues in tissues and products of laying hens.

\section{MATERIALS AND METHODS}

\section{Experimental design}

The study was conducted at a commercial layer farm in Lancaster County, with coordinates 4005'51.37" N 76³3'29.75" W elev 365 $\mathrm{ft}$, eye alt $3920 \mathrm{ft}$ PA. Eight hundred Bovans white caged hens lay at 30-weeks of age, were distributed into 4 treatments that consists of 200 hens per treatment based on inclusion levels of HSC. The control diet $(\mathrm{C} 0)$ - regular diet with no HSC, $(\mathrm{H} 10)$ - basal diet with $10 \% \mathrm{HSC},(\mathrm{H} 20)$ - control diet with $20 \% \mathrm{HSC},(\mathrm{H} 30)$-control diet with $30 \%$ HSC. Each treatment comprised of 8 cages of 25 hens each per replicate. Observations per protocol were made over a timeline of 19 weeks.

\section{Acclimation of test animals}

In order to eliminate the impact of the new ingredient and its differential inclusion levels, the hens under study were subjected to a period of acclimatization for 3 weeks when the respective treatments were fed with the study diets allowing for acclimatization of feed consumption and gut environment. Observations and data from the period of acclimation were not considered for the purpose of this study.

\section{Environment and management}

All the hens under study were subjected to the following 
environmental and management uniformly. Special feed troughs were designed to bypass the existing auto-feeders and the hens were fed manually once a day. An iso-caloric, iso-nitrogenous diet with nutrient levels set at $25 \mathrm{lb} / 100$ hens/day consumption as per breed standard was designed across all treatments. Continuous water, identical environment and management were offered uniformly across treatments. Hens were weighed on cage basis prior to start of the experiment and composition of hens per cage was managed for uniformity of body weight across treatments. Environmental conditions were maintained at $23.33-24.44^{\circ} \mathrm{C}$ house temperature, $40-60 \%$ humidity, 30 Lux lighting for $15-16 \mathrm{~h}$ of lighting per day and air movement between 2550 and $3400 \mathrm{~m}^{3} / \mathrm{h}$ per 1000 hens. The general performance data of hens under study were compared from time to time with rest of the commercial layer house to ensure no unexpected or significant differences were noticed.

\section{Inclusion and exclusion criteria}

In order to establish uniformity of population across treatments, the cages were individually weighed for initial weights and, hens moved between cages so as to maintain a total body weight difference not exceeding $2.5 \%$. These weight-adjusted cages were then randomized within the 32 cage locations with 2 cages of same treatment together. A plastic plate was installed between each cage thus preventing hens from picking feed from adjacent cage feeder. Ailing and visually sick hens were weighed, euthanized, necropsied and disposed of per farm disposal policy; culled hens from the study were not replaced. However, necessary feed adjustments were made whenever culling was required. Medication required was applied across treatment to maintain uniformity and consistency.

\section{Nutritional composition of HSC and finished feed}

The analysis of the nutritional composition of HSC and the study feeds formulated with HSC are presented in Table 1 and the formulation of the feed is presented in Table 2.

\section{Feeding program}

Study hens were offered a uniform free-choice restricted amount of feed at $25 \mathrm{lb} / 100$ per day. At this level, it was expected that the hens consumed nutrients per breed recommendation for the age and stage of production Bovan Management and commercial Product Guide (2019).. The feed intake was kept constant across all treatments. A pre-weighed $6.25 \mathrm{lb}$ of feed was provided to each cage of 25 hens every day at the same time.

\section{Study parameters, test and analytical methods}

\section{Fatty acid profile}

Eggs: Three samples from each treatment was selected and the mean fatty acid values were expressed as percentage of egg weight (Cherian et al., 2007; Jing et al., 2017) along with linoleic to linolenic acid ratio. The fatty acid composition was determined using standard gas chromatographic techniques of the fatty acid methyl esters (AOAC, 1990, method 969.33), with C17:1 fatty acid (Nu-Chek Prep, Inc., Elysian, MN) used as an internal standard. Total lipids were extracted from the test diets, egg yolks, breasts, and abdominal fat by homogenization in chloroform/methanol (2:1, $\mathrm{v} / \mathrm{v}$ ) according to the methods of Folch et al. (1957). After centrifugation, the organic phase was collected and evaporated under a nitrogen stream. The lipid extracts obtained were transesterified with methanolysis ( $1 \%(\mathrm{v} / \mathrm{v})$ sulfuric acid in methanol for 3 $\mathrm{h}$ at $70^{\circ} \mathrm{C}$. After cooling, the resulting fatty acid methyl esters (FAMEs) were extracted with hexane and transferred into gas chromatography (GC) vials. All solvents contained $0.005 \%(\mathrm{v} / \mathrm{v})$ butylated hydroxyanisole (BHA) as an antioxidant. FAMEs were then separated and quantified with a Varian450-GC with CP-8400 autosampler, equipped with a flame ionization detector and a GC column (length $30 \mathrm{~m}$, inner diameter $0.25 \mathrm{~mm}$ and film thickness $0.25 \mu \mathrm{m}, \mathrm{DB}-225 \mathrm{MS}$ ) (Agilent Technologies, Mississauga, ON, Canada). Nitrogen was the carrier gas at a column flow rate of 1 $\mathrm{ml} / \mathrm{min}$. The inlet split ratio was set at 10:1. The oven temperature programming was as follows: $60^{\circ} \mathrm{C}$ for $1.5 \mathrm{~min}$, raised to $180^{\circ} \mathrm{C}$ at $20^{\circ} \mathrm{C}$ per minute, $205^{\circ} \mathrm{C}$ at $6^{\circ} \mathrm{C} / \mathrm{min}, 220^{\circ} \mathrm{C}$ at $2^{\circ} \mathrm{C} / \mathrm{min}$ for $4 \mathrm{~min}$, and $240^{\circ} \mathrm{C}$ at $10^{\circ} \mathrm{C} / \mathrm{min}$ for $3 \mathrm{~min}$. The injector and detector temperature were set at 260 and $290^{\circ} \mathrm{C}$, respectively. FAMEs were identified by comparison of retention times to known lipid standards (Nu-Chek Prep, Inc., Elysian, MN) (Folch et al., 1957; Jing et al., 2017)

Breast meat and abdominal fat (\%): The fatty acid profile of breast meat and abdominal fat was analyzed using the fatty acid procedure of Eurofins Laboratory, Madison, WI, Eurofins, as published by Folch et al. (1957) and Jing et al. (2017). A procedure similar to composite sample for egg quality parameters was followed for preparing samples of right breast meat and right abdominal fat of study hens, as follows: collect samples from 3 hens from 8 cages per treatment for a total of 24 breast or fat samples. Prepare 3 replicates of 8 samples each with 1 sample from each of the cages, mix the 8 samples from each cage, homogenize for a minute, pack in a sterile plastic bag previously identified with details of treatment. This makes 1 composite sample. Prepare 3 such composite replicates per treatment. Repeat the procedure for other treatments.

\section{Hemp cannabinoid residues}

\section{Eggs}

Using whole egg composite sampling as described earlier, 3 replicate samples per treatment were submitted for hemp cannabinoid analysis of the eggs. Ice packed and preserved samples of organs and tissues were shipped overnight for the analysis of the residues of various hemp cannabinoids to Eurofins Laboratory, Madison, WI, method 2018.11, (AOAC, 1990) International (Modified by Lukas et al., 2018).

\section{Blood}

$3 \mathrm{ml}$ of blood were pooled from the wing vein and transferred to a heparinized coated tube from a hen per cage or 8 hens per treatment; the samples were stored for $24 \mathrm{~h}$ in a freezer at $-4^{\circ} \mathrm{C}$ and the following day, they were shipped in dry ice pack to Eurofins laboratory (Madison, WI 53704 USA) for the analysis of hemp cannabinoids residues at weeks 8 and 16; the analysis was performed 7 days post collection. The whole blood samples were processed under refrigeration temperatures and shipped to Eurofins Laboratory for analysis of hemp cannabinoid residues.

\section{Breast meat and abdominal fat}

The hemp cannabinoid residue profiles of breast meat and 
Table 1. Hemp seed cake and Feed nutritional analysis (\%).

\begin{tabular}{|c|c|c|c|c|c|c|c|}
\hline \multirow{2}{*}{ Nutrients } & \multirow{2}{*}{ HSC } & \multirow{2}{*}{ SD } & \multicolumn{4}{|c|}{ Hemp seed cake Treatments } & \multirow{2}{*}{ Pooled SD } \\
\hline & & & Co & $\mathrm{H} 10$ & $\mathrm{H} 2 \mathrm{O}$ & $\mathrm{H} 30$ & \\
\hline Moisture & 7.53 & 0.31 & 12.12 & 11.21 & 10.03 & 8.40 & 0.34 \\
\hline Protein (crude) & 32.06 & 0.30 & 14.81 & 16.31 & 16.75 & 16.57 & 0.49 \\
\hline Fat (crude) & 9.02 & 0.03 & 2.70 & 5.57 & 8.78 & 11.47 & 0.27 \\
\hline Fiber (crude) & 32.21 & 0.44 & 1.79 & 4.92 & 7.07 & 9.82 & 0.46 \\
\hline Ash & 5.38 & 0.05 & 11.27 & 11.48 & 12.71 & 12.21 & 0.33 \\
\hline \multicolumn{8}{|l|}{ Minerals } \\
\hline $\mathrm{Ca}$ & 0.17 & 0.01 & 3.38 & 3.18 & 3.61 & 3.45 & 0.31 \\
\hline$P$ & 0.71 & 0.47 & 0.50 & 0.50 & 0.56 & 0.57 & 0.08 \\
\hline $\mathrm{Na}$ & 0.01 & 0.00 & 0.14 & 0.14 & 0.16 & 0.15 & 0.02 \\
\hline $\mathrm{Mg}$ & 0.48 & 0.01 & 0.17 & 0.21 & 0.26 & 0.28 & 0.01 \\
\hline $\mathrm{Mn}(\mathrm{mg} / \mathrm{lb})$ & 60.46 & 0.58 & 35.68 & 42.52 & 61.36 & 65.91 & 6.40 \\
\hline $\mathrm{Fe}(\mathrm{mg} / \mathrm{lb})$ & 60.76 & 2.01 & 128.86 & 118.18 & 118.86 & 110.91 & 23.41 \\
\hline $\mathrm{Zn}(\mathrm{mg} / \mathrm{lb})$ & 35.38 & 0.56 & 39.16 & 40.73 & 56.14 & 58.18 & 7.12 \\
\hline $\mathrm{Cu}(\mathrm{mg} / \mathrm{lb})$ & 8.56 & 0.46 & 8.82 & 7.98 & 8.16 & 8.73 & 1.78 \\
\hline K & 0.95 & 0.02 & 0.73 & 0.72 & 0.73 & 0.62 & 0.03 \\
\hline \multicolumn{8}{|l|}{ Amino acids } \\
\hline Methionine & 0.51 & 0.12 & 0.42 & 0.42 & 0.44 & 0.52 & 0.05 \\
\hline Cysteine & 0.34 & 0.05 & 0.24 & 0.23 & 0.22 & 0.24 & 0.04 \\
\hline Lysine & 1.13 & 0.02 & 0.86 & 1.04 & 1.00 & 0.97 & 0.11 \\
\hline Phenylalanine & 1.24 & 0.01 & 0.72 & 0.81 & 0.71 & 0.75 & 0.04 \\
\hline Leucine & 1.93 & 0.02 & 1.34 & 1.45 & 1.25 & 1.29 & 0.07 \\
\hline Isoleucine & 0.91 & 0.01 & 0.52 & 0.69 & 0.52 & 0.61 & 0.06 \\
\hline Threonine & 1.18 & 0.03 & 0.59 & 0.72 & 0.67 & 0.66 & 0.06 \\
\hline Valine & 1.13 & 0.02 & 0.57 & 0.77 & 0.61 & 0.76 & 0.06 \\
\hline Histidine & 0.73 & 0.02 & 0.41 & 0.50 & 0.41 & 0.48 & 0.05 \\
\hline Arginine & 4.00 & 0.05 & 0.93 & 1.26 & 1.39 & 1.82 & 0.06 \\
\hline Aspartic acid & 1.37 & 0.03 & 1.60 & 1.63 & 1.76 & 1.56 & 0.08 \\
\hline Serine & 3.55 & 0.03 & 0.82 & 0.87 & 0.82 & 0.77 & 0.19 \\
\hline Glutamic acid & 1.45 & 0.02 & 2.73 & 2.70 & 2.75 & 2.46 & 0.12 \\
\hline Proline & 4.94 & 0.03 & 1.07 & 1.03 & 0.99 & 0.98 & 0.04 \\
\hline Alanine & 1.16 & 0.01 & 0.78 & 0.84 & 0.70 & 0.78 & 0.05 \\
\hline Tyrosine & 0.89 & 0.01 & 0.51 & 0.54 & 0.50 & 0.51 & 0.04 \\
\hline Tryptophan & 0.27 & 0.00 & 0.10 & 0.11 & 0.19 & 0.13 & 0.02 \\
\hline \multicolumn{8}{|l|}{ Fatty acids } \\
\hline Oleic 18:1 w7 & 1.05 & 0.01 & 0.80 & 1.16 & 1.21 & 1.26 & 0.03 \\
\hline Linoleic 18:2 w6 & 55.26 & 0.05 & 55.30 & 54.59 & 54.73 & 54.91 & 0.31 \\
\hline Linolenic 18:3 w6 & 3.43 & 0.02 & 0.00 & 0.45 & 0.69 & 0.81 & 0.12 \\
\hline Linolenic 18:3w3 & 14.47 & 0.05 & 2.66 & 6.01 & 7.33 & 8.00 & 0.12 \\
\hline 18:2W6/18:3w3 ratio & 3.82 & 0.05 & 20.79 & 9.08 & 7.47 & 6.86 & 0.22 \\
\hline Total \% W3 & 15.34 & 0.06 & 2.66 & 6.10 & 7.63 & 8.23 & 0.13 \\
\hline Total \% W6 & 58.69 & 0.06 & 55.30 & 55.03 & 55.51 & 55.72 & 0.32 \\
\hline
\end{tabular}

$\mathrm{CO}=$ control no HSC, $\mathrm{H} 10: 10 \% \mathrm{HSC}, \mathrm{H} 20: 20 \% \mathrm{HSC}, \mathrm{H} 30: 30 \mathrm{HSC}$, BW=body weight. Data are the mean of three replicates $(\mathrm{n}=3)$ of $\mathrm{HSC}$ and two replicates $(\mathrm{n}=2)$ of each feed type, $\mathrm{SD}=$ standard deviation. breast meat and abdominal fat samples at the end of the study (week 16) from 1 hen per replicate or 8 hens per treatment; the composite paste of the breast and the body fat samples were mixed 
Table 2. Study diets formulated by treatment (lb).

\begin{tabular}{|c|c|c|c|c|}
\hline \multirow{2}{*}{ Ingredients } & \multicolumn{4}{|c|}{ Hemp seed cake treatments } \\
\hline & Co & $\mathrm{H} 10$ & $\mathrm{H} 2 \mathrm{O}$ & $\mathrm{H} 30$ \\
\hline Corn & 1304.70 & 1187.90 & 1066.70 & 919.10 \\
\hline Soybean meal- solvent & 463.00 & 334.00 & 206.00 & 102.00 \\
\hline Calcium chip & 98.00 & 97.00 & 98.00 & 98.00 \\
\hline Limestone & 98.00 & 97.00 & 98.00 & 98.00 \\
\hline Monocalcium phosphate $21 \%$ & 20.40 & 18.10 & 15.80 & 13.30 \\
\hline Salt & 5.09 & 5.13 & 5.17 & 5.22 \\
\hline Methionine, DL & 4.00 & 4.00 & 4.00 & 3.80 \\
\hline Sodium sesquicarbonate & 3.60 & 3.60 & 3.60 & 3.60 \\
\hline Vitamin premix & 1.00 & 1.00 & 1.00 & 1.00 \\
\hline Trace minerals premix & 1.00 & 1.00 & 1.00 & 1.00 \\
\hline Choline, Liq. $70 \%$ & 0.62 & 1.43 & 2.25 & 2.97 \\
\hline Alphagal $280 \mathrm{P}$ & 0.33 & 0.33 & 0.33 & 0.33 \\
\hline Phytase & 0.16 & 0.16 & 0.16 & 0.16 \\
\hline HSC & 0.00 & 200.00 & 400.00 & 600.00 \\
\hline Soybean oil & 0 & 44.00 & 90.00 & 139.00 \\
\hline Lysine sulfate $60 \%$ & 0 & 3.48 & 6.95 & 9.28 \\
\hline Tryptophan & 0 & 0.49 & 0.97 & 1.33 \\
\hline Threonine & 0 & 0.40 & 0.90 & 1.00 \\
\hline Ingredient Total & 2000 & 2000 & 2000 & 2000 \\
\hline \multicolumn{5}{|l|}{ Calculated nutritional composition } \\
\hline Moisture & 11.57 & 13.32 & 16.13 & 17.06 \\
\hline Crude protein & 15.86 & 15.88 & 15.90 & 16.34 \\
\hline Fat (Ether extract) & 2.65 & 5.39 & 8.20 & 11.16 \\
\hline Crude fiber & 1.99 & 5.01 & 8.01 & 11.04 \\
\hline Ash & 12.34 & 11.80 & 11.79 & 10.79 \\
\hline \multicolumn{5}{|l|}{ Minerals (\%) } \\
\hline Avail Ca & 4.17 & 4.11 & 4.13 & 4.12 \\
\hline Avail P & 0.44 & 0.44 & 0.44 & 0.44 \\
\hline $\mathrm{Na}$ & 0.17 & 0.17 & 0.17 & 0.17 \\
\hline $\mathrm{Cl}$ & 0.195 & 0.195 & 0.195 & 0.195 \\
\hline Poultry Metabolizable energy (kcal//lb) ME & 1290.23 & 1290.64 & 1290.62 & 1290.39 \\
\hline \multicolumn{5}{|l|}{ Amino acids } \\
\hline Lysine, digestible & 0.75 & 0.76 & 0.78 & 0.79 \\
\hline Methionine, dig & 0.43 & 0.43 & 0.43 & 0.42 \\
\hline Met \& Cys, dig & 0.65 & 0.65 & 0.64 & 0.63 \\
\hline Tryptophan, dig & 0.17 & 0.17 & 0.17 & 0.16 \\
\hline Threonine, dig & 0.53 & 0.53 & 0.52 & 0.52 \\
\hline Phenylalanine, dig & 0.74 & 0.69 & 0.64 & 0.61 \\
\hline Leucine, dig & 1.32 & 1.22 & 1.12 & 1.05 \\
\hline Histidine, dig & 0.40 & 0.37 & 0.35 & 0.34 \\
\hline
\end{tabular}

and equally distributed into 3 composite samples $(n=3)$ as replicates per treatment for statistical analysis. The composite breast meat and abdominal fat samples were put in plastic bags previously identified with the corresponding color-coded treatment 
identification; then samples were shipped to Eurofins Laboratory, Madison, WI, USA for analysis.

\section{Liver, kidney and spleen}

The hemp cannabinoid residue profile in liver, kidney and spleen was determined at week 16 by collecting $1 \mathrm{~cm}$ segment of liver, kidney and the entire spleen. A composite sample procedure was followed. Collect samples from one hen per cage (8 birds per treatment) - a total of 32 samples. Prepare 3 composite samples per treatment with sub-samples from each of the 8 cages per treatment. Repeat the procedure for other treatments. The composite organ samples were put in plastic bags previously identified with the corresponding color-coded treatment identification; samples were then shipped to Eurofins Laboratory, Madison, WI, USA for analysis.

\section{Statistical analysis}

The hen body weight, fatty acid values from abdominal fat, breast meat and eggs were analyzed as a completely randomized design with cage as the experimental unit using the General Linear Model Procedure (PROC GLM) of SAS (SAS, 2012). The significant treatment mean separation was carried out with the Tukey Multiple Range test with a probability of error of $5 \%(\mathrm{P}<0.05)$.

\section{RESULTS AND DISCUSSION}

The analysis of nutritional composition of HSC and feeds formulated with HSC are presented in Table 1. In general, the nutritional composition results were within the expected levels and in agreement with the results in available published literature (Silverside and Lefrancois, 2005; Halle and Schone, 2013; Mierliță, 2019). The omega 6/omega 3 ratios in feed were reduced with the increase of the HSC levels. The 18:2 W6 (Omega 6)/18:3 W3 (omega 3) in feed was reduced from 20.79 in the control treatment to 9.08 in the $\mathrm{H} 10,7.47$ in the $\mathrm{H} 20$ and 6.86 in the $\mathrm{H} 30$ (Table 1). The hemp cannabinoid residue levels of finished feed (Table 3 ) were reported to be below the laboratory detectable levels and under the legal limits of $0.3 \%$ across all treatments.

A general trend of reduced overall body weight across all treatments including control was noticed during the study. Feeding HSC to laying hens showed improved mean weekly body weights compared to the control treatment (Table 4) that was statistically significant at higher levels of inclusion. The trend in general showed no difference between control and $10 \%$ inclusion level, however, presented a positive trend at 20 and 30\% across most part of the study. The mean of weekly mean body weights at the end of the study were higher at the 20 and $30 \%$ HSC fed hens over the control; however the difference was not statistically significant between 0 and $10 \%$ and between 20 and $30 \%$ (Table 4).

The results of mean fatty acid profiles of eggs presented in Table 5 showed evidence of significant influence of feeding HSC in total fatty acids which was significantly $(\mathrm{P}<0.05)$ increased from $9.18 \%$ in the control to $9.97 \%$ in the $\mathrm{H} 20$; no significant effect was observed for total fatty acid in the $\mathrm{H} 10$ and $\mathrm{H} 30$ treatments. The supplementation of $\mathrm{HSC}$ increased $(\mathrm{P}<0.05)$ the recorded levels of omega 3 and 6 in eggs with each increment level of HSC supplemented in the feed. The levels of omega 6 were increased from $1.45 \%$ in the control to $2.18,2.61$ and $2.94 \%$ in the $\mathrm{H} 10, \mathrm{H} 20$ and $\mathrm{H} 30$, respectively (Table 5). There was a decline in the level of omega-9 which was reduced from $3.53 \%$ in the control to $3.18,3.06$ and $2.77 \%$ in the $\mathrm{H} 10, \mathrm{H} 20$ and $\mathrm{H} 30$, respectively. The Polyunsaturated fatty acid (PUFA), Linoleic acid (LA) and alpha-linolenic acid (ALA) levels in the eggs significantly increased over control with increasing levels of HSC supplementation (Table 5). A significant corresponding reduction in LA:ALA ratio in eggs was noticed with greater inclusion levels of HSC. The LA:ALA ratios were reduced from 45.56 in the control to $18.86,15.99$ and 13.48 in the $\mathrm{H} 10, \mathrm{H} 20$ and $\mathrm{H} 30$, respectively (Table 5 ). The levels of monounsaturated fatty acids (MUFA) showed a significant reduction over the control with increasing levels of HSC except at $10 \%$ which showed only a numerical reduction. The total cisfatty acid levels of all HSC fed groups were significantly higher over control showed an increasing trend with HSC inclusion which was statistically significant except between 20 and $30 \%$. The breast meat fatty acid profile determined at the end of the study showed no significant difference $(P>0.05)$ due to supplementation of HSC in the diet of laying hens (Table 6); however, the levels of fatty acids in the abdominal fat determined at the end of the study (Table 7) shows that there were no significant differences $(P>0.05)$ in the total fatty acid profile of abdominal fat across the treatments, however, there was a clear trend of increased poly-unsaturated fatty acids (PUFA), Omega 3 and 6 fatty acids and decrease of Omega 9 fatty acids, with the increasing levels of HSC noted, though an inconsistent statistical significance was observed. The levels of total cis-unsaturated fatty acid levels differed significantly between the HSC fed treatment with control, however the same between HSC fed treatments were not significant. The monounsaturated fatty acid levels were significantly reduced in all HSC treatments compared to control and the differences between treatments were significant $(P<0.05)$ except between $20 \%$ and $30 \%$ HSC inclusion.

The mean cannabinoid residue levels, including delta9-tetrahydrocannabidiol were below laboratory detectable levels of $0.0025 \%$ for egg samples (Table 8 ). The cannabinoid and related component levels of eggs in HSC treated treatments were not different from those of control tested at both intervals of the study (Table 8). The values for all cannabinoid and related compounds in the eggs were below the laboratory detectable levels regardless of the level of inclusion of HSC (Table 8) and 
Table 3. Hemp cannabinoid residues of finished diets $(<\%)$.

\begin{tabular}{lccccc}
\hline \multirow{2}{*}{ Cannabinoids } & \multicolumn{5}{c}{ Hemp seed cake treatments } \\
\cline { 2 - 6 } & HSC & C0 & H10 & H20 & H30 \\
\hline CBDVA & $<0.005$ & $<0.005$ & $<0.005$ & $<0.005$ & $<0.005$ \\
CBDV & $<0.005$ & $<0.005$ & $<0.005$ & $<0.005$ & $<0.005$ \\
CBDA & $<0.005$ & $<0.005$ & $<0.005$ & $<0.005$ & $<0.005$ \\
CBGA & $<0.005$ & $<0.005$ & $<0.005$ & $<0.005$ & $<0.005$ \\
CBG & $<0.005$ & $<0.005$ & $<0.005$ & $<0.005$ & $<0.005$ \\
CBD & $<0.005$ & $<0.005$ & $<0.005$ & $<0.005$ & $<0.005$ \\
THCV & $<0.005$ & $<0.005$ & $<0.005$ & $<0.005$ & $<0.005$ \\
CBN & $<0.005$ & $<0.005$ & $<0.005$ & $<0.005$ & $<0.005$ \\
Delta 9-THC & $<0.005$ & $<0.005$ & $<0.005$ & $<0.005$ & $<0.005$ \\
Delta 8-THC & $<0.005$ & $<0.005$ & $<0.005$ & $<0.005$ & $<0.005$ \\
THCA & $<0.005$ & $<0.005$ & $<0.005$ & $<0.005$ & $<0.005$ \\
CBC & $<0.005$ & $<0.005$ & $<0.005$ & $<0.005$ & $<0.005$ \\
THCVA & $<0.005$ & $<0.005$ & $<0.005$ & $<0.005$ & $<0.005$ \\
CBNA & $<0.005$ & $<0.005$ & $<0.005$ & $<0.005$ & $<0.005$ \\
CBCA & $<0.005$ & $<0.005$ & $<0.005$ & $<0.005$ & $<0.005$ \\
CBL & $<0.005$ & $<0.005$ & $<0.005$ & $<0.005$ & $<0.005$ \\
Total cannabinoids & $<0.005$ & $<0.005$ & $<0.005$ & $<0.005$ & $<0.005$ \\
Total THC & $<0.015$ & $<0.01$ & $<0.01$ & $<0.01$ & $<0.01$ \\
Total CBD & $<0.015$ & $<0.01$ & $<0.01$ & $<0.01$ & $<0.01$ \\
\hline
\end{tabular}

$\mathrm{HSC}=\mathrm{Hemp}$ seed cake, $\mathrm{C} 0=$ control no HSC, $\mathrm{H} 10: 10 \% \mathrm{HSC}, \mathrm{H} 20: 20 \% \mathrm{HSC}, \mathrm{H} 30: 30 \% \mathrm{HSC}, \mathrm{SD}=$ standard deviation, BW=body weight, Data are the mean of three replicates $(n=3)$ of HSC and two replicates $(n=2)$ per feed type. $\mathrm{CBDVA}=$ Cannabidivarinic $\mathrm{Acid}, \mathrm{CBDV}=$ Cannabidivarin, $\mathrm{CBDA}=$ cannabidiolic acid, $\mathrm{CBGA}=$ Cannabigerolic Acid, $\mathrm{CBD}=$ Cannabidiol, $\mathrm{THCV}=$ Tetrahydrocannabivarin $(\mathrm{THCV}), \mathrm{CBN}=\mathrm{Cannabinol}$, Delta $9-\mathrm{THC}=\Delta-9$ tetrahydrocannabinol, Delta $8-\mathrm{THC}=\Delta-8$ tetrahydrocannabinol, $\mathrm{THCA}=$ Tetrahydrocannabinolic acid, $\mathrm{CBC}=$ cannabichromene, THCVA = Tetrahydrocannabivarinic acid, CBNA= Cannabinolic acid, CBCA=cannabichromenic acid, CBL=cannabicyclol.

Table 4. Mean body weight of hens (lb/hen)

\begin{tabular}{|c|c|c|c|c|c|c|}
\hline \multirow{2}{*}{ Weeks } & \multicolumn{4}{|c|}{ Hemp seed cake treatment } & \multirow{2}{*}{ P-Value } & \multirow{2}{*}{ SD } \\
\hline & $\mathrm{CO}$ & H10 & $\mathrm{H} 2 \mathrm{O}$ & H30 & & \\
\hline 1 & 3.40 & 3.41 & 3.40 & 3.40 & 0.931 & 0.04 \\
\hline 2 & $3.31^{\mathrm{C}}$ & $3.37^{b c}$ & $3.47^{\mathrm{a}}$ & $3.45^{\mathrm{ab}}$ & 0.0001 & 0.06 \\
\hline 4 & $3.31^{\mathrm{b}}$ & $3.37^{\mathrm{ab}}$ & $3.45^{a}$ & $3.46^{\mathrm{a}}$ & 0.0005 & 0.07 \\
\hline 6 & $3.29^{b}$ & $3.34^{\mathrm{b}}$ & $3.45^{a}$ & $3.45^{a}$ & 0.0003 & 0.08 \\
\hline 8 & $3.22^{b}$ & $3.30^{\mathrm{ab}}$ & $3.41^{\mathrm{a}}$ & $3.41^{\mathrm{a}}$ & 0.0003 & 0.09 \\
\hline 10 & $3.17^{b}$ & $3.31^{a}$ & $3.41^{\mathrm{a}}$ & $3.38^{a}$ & 0.0001 & 0.09 \\
\hline 12 & $3.13^{\mathrm{c}}$ & $3.21^{b c}$ & $3.29^{\mathrm{ab}}$ & $3.36^{a}$ & 0.0004 & 0.10 \\
\hline 14 & $3.13^{\mathrm{a}}$ & $3.19^{\mathrm{ac}}$ & $3.24^{\mathrm{c}}$ & $3.36^{b}$ & 0.0002 & 0.09 \\
\hline 16 & $3.12^{\mathrm{c}}$ & $3.18^{b c}$ & $3.24^{\mathrm{ab}}$ & $3.35^{\mathrm{a}}$ & 0.0001 & 0.08 \\
\hline Mean BW & $3.21^{\mathrm{c}}$ & $3.28^{\mathrm{bc}}$ & $3.37^{\mathrm{ab}}$ & $3.40^{a}$ & 0.0001 & 0.07 \\
\hline
\end{tabular}

$\mathrm{CO}=$ control no HSC, $\mathrm{H} 10: 10 \% \mathrm{HSC}, \mathrm{H} 20: 20 \% \mathrm{HSC}, \mathrm{H} 30: 30 \% \mathrm{HSC}, \mathrm{BW}=$ body weight. Data are the mean of eight replica $(n=8)$ per treatment, Means with different superscripts are significantly different $(P<0.05)$. SD $=$ standard deviation

in the control.

Supplementation of HSC did not significantly affect the blood cannabinoid and related component profiles of hens during the study (Table 9). The levels of total hemp 
Table 5. Fatty acids in eggs (\%).

\begin{tabular}{lcccccc}
\hline \multirow{2}{*}{ Fatty acids } & \multicolumn{3}{c}{ Hemp seed cake treatment } & P-value & SD \\
\cline { 2 - 5 } & C0 & H10 & H20 & H30 & & 0.067 \\
Saturated fatty acids & 3.39 & 3.39 & 3.48 & 3.18 & 0.117 \\
Total cis fatty acids & $5.32^{\mathrm{c}}$ & $5.68^{\mathrm{b}}$ & $6.00^{\mathrm{a}}$ & $6.02^{\mathrm{a}}$ & 0.002 & 0.153 \\
Mono-unsaturated fatty acids (MUFA) & $3.87^{\mathrm{a}}$ & $3.39^{\mathrm{b}}$ & $3.23^{\mathrm{b}}$ & $2.87^{\mathrm{c}}$ & 0.0001 & 0.123 \\
Polyunsaturated fatty acids (PUFA) & $1.45^{\mathrm{d}}$ & $2.29^{\mathrm{c}}$ & $2.78^{\mathrm{b}}$ & $3.15^{\mathrm{a}}$ & 0.0001 & 0.118 \\
Omega-3 & $0.070^{\mathrm{d}}$ & $0.220^{\mathrm{c}}$ & $0.290^{\mathrm{b}}$ & $0.346^{\mathrm{a}}$ & 0.0001 & 0.013 \\
Omega-6 & $1.45^{\mathrm{d}}$ & $2.18^{\mathrm{c}}$ & $2.61^{\mathrm{b}}$ & $2.94^{\mathrm{a}}$ & 0.0001 & 0.11 \\
Omega-9 & $3.53^{\mathrm{a}}$ & $3.18^{\mathrm{b}}$ & $3.06^{\mathrm{b}}$ & $2.77^{\mathrm{c}}$ & 0.0003 & 0.116 \\
Total fatty acids & $9.18^{\mathrm{a}}$ & $9.53^{\mathrm{ab}}$ & $9.97^{\mathrm{b}}$ & $9.65^{\mathrm{ab}}$ & 0.048 & 0.279 \\
Linoleic acid (LA) & $1.15^{\mathrm{a}}$ & $1.87^{\mathrm{b}}$ & $2.28^{\mathrm{c}}$ & $2.63^{\mathrm{d}}$ & 0.0001 & 0.102 \\
a-Linolenic acid (ALA) & $0.03^{\mathrm{a}}$ & $0.10^{\mathrm{b}}$ & $0.14^{\mathrm{c}}$ & $0.20^{\mathrm{d}}$ & 0.0001 & 0.009 \\
LA: ALA ratio & $45.56^{\mathrm{a}}$ & $18.86^{\mathrm{b}}$ & $15.99^{\mathrm{c}}$ & $13.48^{\mathrm{d}}$ & 0.0001 & 1.71 \\
\hline
\end{tabular}

$\mathrm{CO}=$ control no HSC, $\mathrm{H} 10: 10 \% \mathrm{HSC}, \mathrm{H} 20: 20 \% \mathrm{HSC}, \mathrm{H} 30: 30 \% \mathrm{HSC}, \mathrm{SD}=$ standard deviation, $\mathrm{BW}=$ body weight. Data are the mean of three composite replicates $(n=3)$ per treatment. Means with different superscripts are significantly different $(P<0.05)$.

Table 6. Fatty acid profile of breast meat (\%).

\begin{tabular}{|c|c|c|c|c|c|c|}
\hline \multirow{2}{*}{ Fatty acids } & \multicolumn{4}{|c|}{ Hemp seed cake treatments } & \multirow{2}{*}{ P-value } & \multirow{2}{*}{ Pooled SD } \\
\hline & $\mathrm{CO}$ & H10 & $\mathrm{H} 20$ & H30 & & \\
\hline Saturated fatty acids & 0.29 & 0.24 & 0.27 & 0.24 & 0.88 & 0.09 \\
\hline TCUSA & 0.50 & 0.52 & 0.63 & 0.64 & 0.90 & 0.29 \\
\hline MUFA & 0.25 & 0.22 & 0.25 & 0.24 & 0.99 & 0.14 \\
\hline PUSFA & 0.25 & 0.30 & 0.38 & 0.40 & 0.62 & 0.15 \\
\hline Omega3 & 0.03 & 0.02 & 0.03 & 0.04 & 0.50 & 0.01 \\
\hline Omega 6 & 0.26 & 0.29 & 0.38 & 0.38 & 0.67 & 0.15 \\
\hline Omega 9 & 0.25 & 0.21 & 0.24 & 0.23 & 0.98 & 0.13 \\
\hline TFA & 0.83 & 0.80 & 0.93 & 0.92 & 0.40 & 0.97 \\
\hline
\end{tabular}

Abbreviations: $\mathrm{CO}=$ control no $\mathrm{HSC}, \mathrm{H} 10: 10 \% \mathrm{HSC}, \mathrm{H} 20: 20 \% \mathrm{HSC}, \mathrm{H} 30: 30 \% \mathrm{HSC}$. Data are the mean of three composite ( $=3$ ) replicates per treatment. $S D=$ pooled standard deviation, Means with different superscripts are significantly different $(P<0.05)$. TCUSA = Total Cis Unsaturated Fatty Acids, MUFA=monounsaturated fatty acids, PUSFA=polyunsaturated fatty acids, TFA= total fatty acids.

cannabinoids and individual components determined at the end of the study in breast meat were reported to be below the laboratory detectable levels (Table 10) in all experimental groups, including the control; similarly, the levels of total hemp cannabinoids and individual components determined at the end of the study in abdominal fat samples were found to be below the laboratory detectable levels (Table 11) in all experimental groups, including the control. An extensive assay of liver, kidney and spleen revealed the levels of cannabinoids and THC to be below the laboratory detectable levels in all experimental groups, including the control (Table 12).

The nutritional profile of HSC makes this interesting as a potential feed ingredient in animals feeding; however, concern still remains due to the possibility of cannabinoid and $\mathrm{THC}$ residues in animal organs and tissues. Although HSC has not gained due attention in the USA, its nutritional properties and applications have long been recognized and valued as food for both humans and domesticated animals in China, India, Russia, Eastern Europe and Canada. There are not sufficient published references about the use of hemp seed cake on laying hens; most of the published literature on this subject and related areas is in other species and with using whole hemp seed or hemp oil or other hemp products. Given the extremely limited published research on the safety of feeding HSC in livestock the authors are constrained with few supporting references to quote on the findings. The authors have attempted to align with the closest possible references. 
Table 7. Fatty acid profile of abdominal fat (\%).

\begin{tabular}{|c|c|c|c|c|c|c|}
\hline \multirow{2}{*}{ Fatty acids } & \multicolumn{4}{|c|}{ Hemp seed cake treatments } & \multirow{2}{*}{ P-value } & \multirow{2}{*}{ SD } \\
\hline & $\mathrm{CO}$ & $\mathrm{H} 10$ & $\mathrm{H} 2 \mathrm{O}$ & $\mathrm{H} 30$ & & \\
\hline Saturated fatty acids & $23.77^{\mathrm{a}}$ & $20.73^{\mathrm{b}}$ & $17.17^{\mathrm{c}}$ & $15.33^{\mathrm{c}}$ & 0.0002 & 1.29 \\
\hline TCUSA & $51.93^{b}$ & $59.40^{\mathrm{a}}$ & $62.27^{\mathrm{a}}$ & $61.00^{\mathrm{a}}$ & 0.0261 & 3.48 \\
\hline MUFA & $33.30^{\mathrm{a}}$ & $28.53^{\mathrm{b}}$ & $24.03^{c}$ & $21.93^{c}$ & 0.0015 & 2.35 \\
\hline PUFA & $18.63^{c}$ & $30.87^{\mathrm{b}}$ & $38.23^{\mathrm{a}}$ & $39.07^{\mathrm{a}}$ & 0.0001 & 2.12 \\
\hline Omega3 & $0.57^{c}$ & $2.03^{b}$ & $3.09^{a}$ & $3.42^{\mathrm{a}}$ & 0.0001 & 0.21 \\
\hline Omega 6 & $18.93^{\mathrm{C}}$ & $30.20^{\mathrm{b}}$ & $36.90^{\mathrm{a}}$ & $37.43^{\mathrm{a}}$ & 0.0001 & 2.08 \\
\hline Omega 9 & $30.4^{\mathrm{b}}$ & $26.93^{\mathrm{ab}}$ & $23.03^{\mathrm{ac}}$ & $21.03^{\mathrm{C}}$ & 0.0041 & 2.25 \\
\hline TFA & 79.60 & 84.00 & 83.33 & 80.03 & 0.574 & 4.63 \\
\hline
\end{tabular}

$\mathrm{CO}=$ control no HSC, $\mathrm{H} 10: 10 \% \mathrm{HSC}, \mathrm{H} 20: 20 \% \mathrm{HSC}, \mathrm{H} 30: 30 \% \mathrm{HSC}$; Data are the mean of three composite $(\mathrm{n}=3)$ replicates per treatment.SD=pooled standard deviation. Means with different superscripts are significantly different $(P<0.05)$. TCUSA $=$ Total cis unsaturated fatty acids, MUFA=monounsaturated fatty acids, PUFA=polyunsaturated fatty acids, TFA= total fatty acids.

Table 8. Hemp cannabinoid residues in eggs (<\%).

\begin{tabular}{|c|c|c|c|c|c|c|c|c|}
\hline \multirow{3}{*}{ Cannabinoids } & \multicolumn{4}{|c|}{ Week 8} & \multicolumn{4}{|c|}{ Week 16} \\
\hline & \multicolumn{4}{|c|}{ Hemp seed cake treatments } & \multicolumn{4}{|c|}{ Hemp seed cake treatments } \\
\hline & $\mathrm{CO}$ & $\mathrm{H} 10$ & $\mathrm{H} 2 \mathrm{O}$ & $\mathrm{H} 30$ & $\mathrm{CO}$ & H10 & $\mathrm{H} 2 \mathrm{O}$ & $\mathrm{H} 30$ \\
\hline THCA & $<0.0025$ & $<0.0025$ & $<0.0025$ & $<0.0025$ & $<0.0025$ & $<0.0025$ & $<0.0025$ & $<0.0025$ \\
\hline СВС & $<0.0025$ & $<0.0025$ & $<0.0025$ & $<0.0025$ & $<0.0025$ & $<0.0025$ & $<0.0025$ & $<0.0025$ \\
\hline THCVA & $<0.0025$ & $<0.0025$ & $<0.0025$ & $<0.0025$ & $<0.0025$ & $<0.0025$ & $<0.0025$ & $<0.0025$ \\
\hline CBNA & $<0.0025$ & $<0.0025$ & $<0.0025$ & $<0.0025$ & $<0.0025$ & $<0.0025$ & $<0.0025$ & $<0.0025$ \\
\hline CBCA & $<0.0025$ & $<0.0025$ & $<0.0025$ & $<0.0025$ & $<0.0025$ & $<0.0025$ & $<0.0025$ & $<0.0025$ \\
\hline $\mathrm{CBL}$ & $<0.0025$ & $<0.0025$ & $<0.0025$ & $<0.0025$ & $<0.0025$ & $<0.0025$ & $<0.0025$ & $<0.0025$ \\
\hline${ }^{*}$ Total THC & $<0.0025$ & $<0.0025$ & $<0.0025$ & $<0.0025$ & $<0.0025$ & $<0.0025$ & $<0.0025$ & $<0.0025$ \\
\hline${ }^{\star \star}$ Total CBD & $<0.0025$ & $<0.0025$ & $<0.0025$ & $<0.0025$ & $<0.0025$ & $<0.0025$ & $<0.0025$ & $<0.0025$ \\
\hline
\end{tabular}

$\mathrm{C} 0=$ control no HSC, $\mathrm{H} 10: 10 \% \mathrm{HSC}, \mathrm{H} 20: 20 \% \mathrm{HSC}, \mathrm{H} 30: 30 \% \mathrm{HSC}$, Data are the mean of three composite ( $\mathrm{n}=3$ ) replicates per treatment, Means with different superscripts are significantly different $(P<0.05)$, THCA $=$ Tetrahydrocannabinolic acid, $C B C=$ cannabichromene, THCVA= Tetrahydrocannabivarinic acid, CBNA= Cannabinolic acid, CBCA=cannabichromenic acid, $\mathrm{CBL}=$ cannabicyclol, ${ }^{*}$ Total THC $\left(\mathrm{THC}+(\mathrm{THCAx0} 0.877),{ }^{* *}\right.$ Total CBD $(\mathrm{CBD}+(\mathrm{CBDAx0.877})$

Table 9. Hemp cannabinoid residues in blood (<\%).

\begin{tabular}{lcccccccc}
\hline \multirow{2}{*}{ Cannabinoids } & \multicolumn{3}{c}{$\begin{array}{c}\text { Hemp seed cake treatments } \\
\text { (week 8) }\end{array}$} & \multicolumn{3}{c}{$\begin{array}{c}\text { Hemp seed cake treatments } \\
\text { (week 16) }\end{array}$} \\
\cline { 2 - 9 } & C0 & H10 & H20 & H30 & C0 & H10 & H20 & H30 \\
\hline CBDVA & $<0.0025$ & $<0.0025$ & $<0.0025$ & $<0.0025$ & $<0.0025$ & $<0.0025$ & $<0.0025$ & $<0.0025$ \\
CBDV & $<0.0025$ & $<0.0025$ & $<0.0025$ & $<0.0025$ & $<0.0025$ & $<0.0025$ & $<0.0025$ & $<0.0025$ \\
CBDA & $<0.0025$ & $<0.0025$ & $<0.0025$ & $<0.0025$ & $<0.0025$ & $<0.0025$ & $<0.0025$ & $<0.0025$ \\
CBGA & $<0.0025$ & $<0.0025$ & $<0.0025$ & $<0.0025$ & $<0.0025$ & $<0.0025$ & $<0.0025$ & $<0.0025$ \\
CBG & $<0.0025$ & $<0.0025$ & $<0.0025$ & $<0.0025$ & $<0.0025$ & $<0.0025$ & $<0.0025$ & $<0.0025$ \\
CBD & $<0.0025$ & $<0.0025$ & $<0.0025$ & $<0.0025$ & $<0.0025$ & $<0.0025$ & $<0.0025$ & $<0.0025$ \\
THCV & $<0.0025$ & $<0.0025$ & $<0.0025$ & $<0.0025$ & $<0.0025$ & $<0.0025$ & $<0.0025$ & $<0.0025$ \\
CBN & $<0.0025$ & $<0.0025$ & $<0.0025$ & $<0.0025$ & $<0.0025$ & $<0.0025$ & $<0.0025$ & $<0.0025$ \\
Delta 9-THC & $<0.0025$ & $<0.0025$ & $<0.0025$ & $<0.0025$ & $<0.0025$ & $<0.0025$ & $<0.0025$ & $<0.0025$ \\
Delta 8-THC & $<0.0025$ & $<0.0025$ & $<0.0025$ & $<0.0025$ & $<0.0025$ & $<0.0025$ & $<0.0025$ & $<0.0025$ \\
\hline
\end{tabular}


Table 9. Cont'd

\begin{tabular}{|c|c|c|c|c|c|c|c|c|}
\hline THCA & $<0.0025$ & $<0.0025$ & $<0.0025$ & $<0.0025$ & $<0.0025$ & $<0.0025$ & $<0.0025$ & $<0.0025$ \\
\hline CBC & $<0.0025$ & $<0.0025$ & $<0.0025$ & $<0.0025$ & $<0.0025$ & $<0.0025$ & $<0.0025$ & $<0.0025$ \\
\hline THCVA & $<0.0025$ & $<0.0025$ & $<0.0025$ & $<0.0025$ & $<0.0025$ & $<0.0025$ & $<0.0025$ & $<0.0025$ \\
\hline CBNA & $<0.0025$ & $<0.0025$ & $<0.0025$ & $<0.0025$ & $<0.0025$ & $<0.0025$ & $<0.0025$ & $<0.0025$ \\
\hline CBCA & $<0.0025$ & $<0.0025$ & $<0.0025$ & $<0.0025$ & $<0.0025$ & $<0.0025$ & $<0.0025$ & $<0.0025$ \\
\hline CBL & $<0.0025$ & $<0.0025$ & $<0.0025$ & $<0.0025$ & $<0.0025$ & $<0.0025$ & $<0.0025$ & $<0.0025$ \\
\hline *Total THC & $<0.0025$ & $<0.0025$ & $<0.0025$ & $<0.0025$ & $<0.0025$ & $<0.0025$ & $<0.0025$ & $<0.0025$ \\
\hline${ }^{\star *}$ Total CBD & $<0.0025$ & $<0.0025$ & $<0.0025$ & $<0.0025$ & $<0.0025$ & $<0.0025$ & $<0.0025$ & $<0.0025$ \\
\hline
\end{tabular}

$\mathrm{CO}=$ control no HSC, $\mathrm{H} 10: 10 \% \mathrm{HSC}, \mathrm{H} 20: 20 \% \mathrm{HSC}, \mathrm{H} 30: 30 \mathrm{HSC}$, CBDVA= Cannabidivarinic Acid, CBDV=Cannabidivarin, CBDA= cannabidiolic acid, $\quad \mathrm{CBGA}=$ Cannabigerolic Acid, $\mathrm{CBD}=$ Cannabidiol, $\mathrm{THCV}=$ Tetrahydrocannabivarin $(\mathrm{THCV}), \quad \mathrm{CBN}=\mathrm{Cannabinol}, \quad \mathrm{Delta} 9-\mathrm{THC}=\Delta-9$ tetrahydrocannabinol, Delta $8-\mathrm{THC}=\Delta-8$ tetrahydrocannabinol, THCA $=$ Tetrahydrocannabinolic acid, $\mathrm{CBC}=\mathrm{cannabichromene}, \quad \mathrm{THCVA}=$ Tetrahydrocannabivarinic acid, CBNA $=$ Cannabinolic acid, $C B C A=$ cannabichromenic acid, $C B L=$ cannabicyclol, Data are the mean of eight $(n=8)$ replicates per treatment, Means with different superscripts are significantly different $(P<0.05)$.

${ }^{*}$ Total THC $\left(\mathrm{THC}+(\mathrm{THCAx0.877)}),{ }^{* *}\right.$ Total CBD $(\mathrm{CBD}+(\mathrm{CBDAx0} .877)$.

Table 10. Hemp cannabinoid residues in in breast meat $(<\%)$.

\begin{tabular}{lcccc}
\hline \multirow{2}{*}{ Hemp cannabinoids } & \multicolumn{4}{c}{ Hemp seed cake treatments } \\
\cline { 2 - 4 } & C0 & H10 & H20 & H30 \\
\hline CBDVA & $<0.0025$ & $<0.0025$ & $<0.0025$ & $<0.0025$ \\
CBDV & $<0.0025$ & $<0.0025$ & $<0.0025$ & $<0.0025$ \\
CBDA & $<0.0025$ & $<0.0025$ & $<0.0025$ & $<0.0025$ \\
CBGA & $<0.0025$ & $<0.0025$ & $<0.0025$ & $<0.0025$ \\
CBG & $<0.0025$ & $<0.0025$ & $<0.0025$ & $<0.0025$ \\
CBD & $<0.0025$ & $<0.0025$ & $<0.0025$ & $<0.0025$ \\
THCV & $<0.0025$ & $<0.0025$ & $<0.0025$ & $<0.0025$ \\
CBN & $<0.0025$ & $<0.0025$ & $<0.0025$ & $<0.0025$ \\
Delta 9-THC & $<0.0025$ & $<0.0025$ & $<0.0025$ & $<0.0025$ \\
Delta 8-THC & $<0.0025$ & $<0.0025$ & $<0.0025$ & $<0.0025$ \\
THCA & $<0.0025$ & $<0.0025$ & $<0.0025$ & $<0.0025$ \\
CBC & $<0.0025$ & $<0.0025$ & $<0.0025$ & $<0.0025$ \\
THCVA & $<0.0025$ & $<0.0025$ & $<0.0025$ & $<0.0025$ \\
CBNA & $<0.0025$ & $<0.0025$ & $<0.0025$ & $<0.0025$ \\
CBCA & $<0.0025$ & $<0.0025$ & $<0.0025$ & $<0.0025$ \\
CBL & $<0.0025$ & $<0.0025$ & $<0.0025$ & $<0.0025$ \\
Total Cannabinoids & $<0.0025$ & $<0.0025$ & $<0.0025$ & $<0.0025$ \\
$*$ Total THC & $<0.0025$ & $<0.0025$ & $<0.0025$ & $<0.0025$ \\
$* *$ Total CBD & $<0.0025$ & $<0.0025$ & $<0.0025$ & $<0.0025$ \\
\hline CO & & & $<5$
\end{tabular}

$\mathrm{CO}=$ control no $\mathrm{HSC}, \mathrm{H} 10: 10 \% \mathrm{HSC}, \mathrm{H} 20: 20 \% \mathrm{HSC}, \mathrm{H} 30: 30 \% \mathrm{HSC}$; $\mathrm{SD}=0$, Data are the mean of three composite $(n=3)$ replicates per treatment, CBDVA= Cannabidivarinic Acid, CBDV=Cannabidivarin, CBDA= cannabidiolic acid, $\mathrm{CBGA}=$ Cannabigerolic Acid, $\mathrm{CBD}=$ Cannabidiol, THCV $=$ Tetrahydrocannabivarin (THCV), $\quad \mathrm{CBN}=$ Cannabinol, Delta 9-THC= -9 tetrahydrocannabinol, Delta 8-THC $=\Delta-8$ tetrahydrocannabinol, $\quad \mathrm{THCA}=$ Tetrahydrocannabinolic acid, $\mathrm{CBC}=$ cannabichromene, THCVA=Tetrahydrocannabivarinic acid, CBNA=Cannabinolic acid, CBCA=cannabichromenic acid, $\mathrm{CBL}=$ cannabicyclol, ${ }^{\star}$ Total THC $\left(\mathrm{THC}+(\mathrm{THCAx0.877)})\right.$, ${ }^{* *}$ Total $\mathrm{CBD}(\mathrm{CBD}+(\mathrm{CBDAx0.877)})$.

The prime perceived nutritional value of HSC as an alternative animal feed ingredient is its superior fatty acid composition, with a high contribution of unsaturated and omega fatty acids. The importance and beneficial effects of unsaturated fatty acids and omega fatty acids are well established in both human and animal health (Jing et al., 2017). The general positive trend in total fatty acid levels, a strong Omega 3 and 6 fatty acid levels, 
Table 11. Hemp cannabinoid residues of abdominal fat $(<\%)$.

\begin{tabular}{lcccc}
\hline \multirow{2}{*}{ Hemp cannabinoids } & \multicolumn{4}{c}{ Hemp seed cake treatments } \\
\cline { 2 - 5 } & C0 & H10 & H20 & H30 \\
\hline CBDVA & $<0.0025$ & $<0.0025$ & $<0.0025$ & $<0.0025$ \\
CBDV & $<0.0025$ & $<0.0025$ & $<0.0025$ & $<0.0025$ \\
CBDA & $<0.0025$ & $<0.0025$ & $<0.0025$ & $<0.0025$ \\
CBGA & $<0.0025$ & $<0.0025$ & $<0.0025$ & $<0.0025$ \\
CBG & $<0.0025$ & $<0.0025$ & $<0.0025$ & $<0.0025$ \\
CBD & $<0.0025$ & $<0.0025$ & $<0.0025$ & $<0.0025$ \\
THCV & $<0.0025$ & $<0.0025$ & $<0.0025$ & $<0.0025$ \\
CBN & $<0.0025$ & $<0.0025$ & $<0.0025$ & $<0.0025$ \\
Delta 9-THC & $<0.0025$ & $<0.0025$ & $<0.0025$ & $<0.0025$ \\
Delta 8-THC & $<0.0025$ & $<0.0025$ & $<0.0025$ & $<0.0025$ \\
THCA & $<0.0025$ & $<0.0025$ & $<0.0025$ & $<0.0025$ \\
CBC & $<0.0025$ & $<0.0025$ & $<0.0025$ & $<0.0025$ \\
THCVA & $<0.0025$ & $<0.0025$ & $<0.0025$ & $<0.0025$ \\
CBNA & $<0.0025$ & $<0.0025$ & $<0.0025$ & $<0.0025$ \\
CBCA & $<0.0025$ & $<0.0025$ & $<0.0025$ & $<0.0025$ \\
CBL & $<0.0025$ & $<0.0025$ & $<0.0025$ & $<0.0025$ \\
Total Cannabinoids & $<0.0025$ & $<0.0025$ & $<0.0025$ & $<0.0025$ \\
${ }^{*}$ Total THC & $<0.0025$ & $<0.0025$ & $<0.0025$ & $<0.0025$ \\
${ }^{* *}$ Total CBD & $<0.0025$ & $<0.0025$ & $<0.0025$ & $<0.0025$ \\
\hline
\end{tabular}

Abbreviations: $\mathrm{CO}=$ control no HSC, $\mathrm{H} 10: 10 \%$ HSC, $\mathrm{H} 20: 20 \% \mathrm{HSC}, \mathrm{H} 30: 30 \mathrm{HSC}$, Data are the mean of three composite $(n=3)$ replicates per treatment, CBDVA = Cannabidivarinic Acid, $\mathrm{CBDV}=$ Cannabidivarin, $\quad \mathrm{CBDA}=$ cannabidiolic acid, $\mathrm{CBGA}=$ Cannabigerolic Acid, $\mathrm{CBD}=$ Cannabidiol, THCV $=$ Tetrahydrocannabivarin (THCV), CBN= Cannabinol, Delta $9-\mathrm{THC}=\Delta-9$ tetrahydrocannabinol, Delta $8-\mathrm{THC}=\Delta-8$ tetrahydrocannabinol, THCA $=$ Tetrahydrocannabinolic acid, $\mathrm{CBC}=$ cannabichromene, $\quad \mathrm{THCVA}=$ Tetrahydrocannabivarinic acid, CBNA $=$ Cannabinolic acid, $\mathrm{CBCA}=$ cannabichromenic acid, $\mathrm{CBL}=$ cannabicyclol, ${ }^{*}$ Total $\mathrm{THC} \quad\left(\mathrm{THC}+(\mathrm{THCAx0.877})\right.$, ${ }^{* \star}$ Total $\mathrm{CBD}(\mathrm{CBD}+(\mathrm{CBDA} 0.877)$.

polyunsaturated fatty acids (PUFA), linoleic and linolenic acid levels, cis-fatty acids and trends of reduction in saturated fatty acid levels, monounsaturated fatty acid (MUFA) levels, and linoleic (Omega-6): alpha-linolenic (Omega 3) ratios in egg and abdominal fat, only confirm the beneficial effects of feeding HSC. This reinforces the findings of Gakhar et al. (2012) using hemp seed and Silversides and Lefrancois (2005) using hemp seed meal.

The high unsaturated fatty acid and essential fatty acid - Omega 3 and 6 - levels in eggs may be attributed to their high levels in HSC. This, together with reduction in Omega 9 and saturated fatty acids adds to enhancement of the nutritional profile of eggs. Omega- 9 fatty acids (including oleic acid and erucic acid) unlike Omega-3 and 6 are not considered essential fatty acids. The LA (omega 6): ALA (omega 3) ratios in eggs were reduced from $45.56 \%$ in the control to $18.86,15.99$ and $13.48 \%$ in the $\mathrm{H} 10, \mathrm{H} 2 \mathrm{O}$ and $\mathrm{H} 30$, respectively (Table 5). This reduction of the omega 6/omega 3 ratios is of upmost importance to reduce mortality from cardiovascular diseases. Simopoulos, (2002) reports that the omega 6/omega 3 ratio in Europe and United States is 50 with mortality from cardiovascular disease of $45 \%$ compared to the omega 6/omega 3 ratios of 12 and 1 in Japan and Greenland Eskimos with lower cardiovascular diseases related mortality of just $12 \%$ and $7 \%$, respectively.

The primary concern with feeding HSC to laying hens is its transfer potential of hemp cannabinoid residues, mainly cannabidiol and delta-9-tetrahydrocannabinol. Published research states that a level of $\Delta-9$ tetrahydrocannabinol (THC), a psychoactive substance in the hemp plant (Health Canada, 2012) below $0.3 \%$ is safe for animal feeding (Jing et al., 2017). The current study demonstrates no contribution or transfer of cannabinoid residues to eggs or body tissues as evidenced by laboratory analysis of HSC, finished feed, egg, blood, breast meat, abdominal fat, liver, kidneys, and spleen. The mean hemp cannabinoid component levels, (including cannabidiol and THC) were less than the laboratory detectable level of $0.005 \%$ across study treatments with no significant differences. The fact that the hemp cannabinoids were not detected in the blood, organs and tissues or egg after 16 weeks of HSC feeding sufficiently demonstrates its non-contributory and non- 
Table 12. Hemp cannabinoid residues of liver, kidney and spleen (<\%).

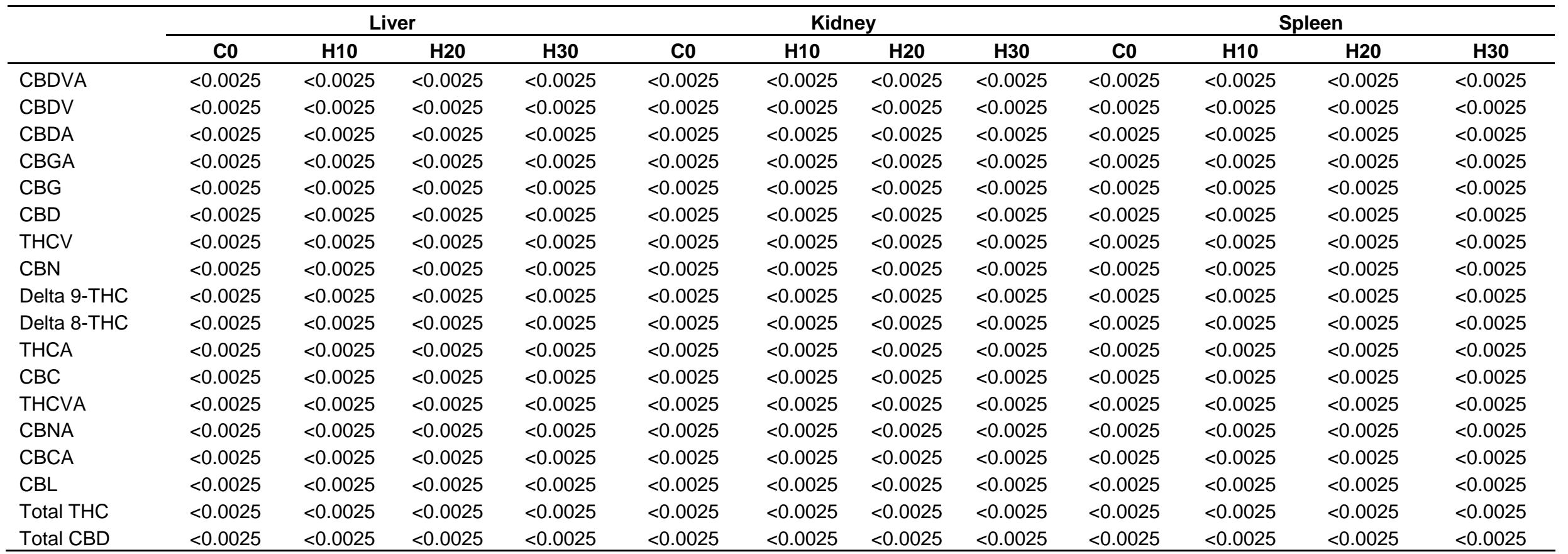

Abbreviations: Hemp seed cake treatments: $\mathrm{CO}=$ control no HSC, $\mathrm{H} 10: 10 \% \mathrm{HSC}, \mathrm{H} 20: 20 \% \mathrm{HSC}, \mathrm{H} 30: 30 \% \mathrm{HSC}$

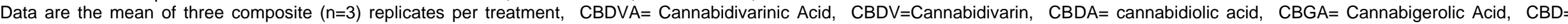

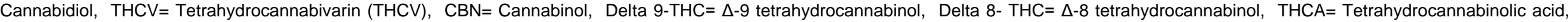
$\mathrm{CBC}=$ cannabichromene, THCVA= Tetrahydrocannabivarinic acid, CBNA= Cannabinolic acid, $\mathrm{CBCA}=\mathrm{cannabichromenic}$ acid, $\mathrm{CBL}=\mathrm{cannabicyclol}$.

transfer nature of such compounds at designed inclusion levels. This finding is an addition to the current knowledge pool of safely feeding HSC to laying hens. The authors have not been able to proper compare with other studies due to the shortage of published literatures about the use of HSC in laying hens. In summary, this study confirms a significant fatty acid enhancement of egg and abdominal fat by feeding HSC and it is safe to be fed, since there was no transfer of cannabinoids or THC.

\section{Conclusion}

The current study has sufficiently evaluated and demonstrated the following conclusions: HSC feeding to commercial laying hens up to $30 \%$ of ration best enhance the deposition of unsaturated fatty acids in eggs and abdominal fat. HSC feeding to commercial laying hens up to $30 \%$ did not transfer psychoactive hemp cannabinoid residues in blood, eggs, body fat, breast meat, liver, kidneys, and spleen.

\section{Recommendations}

Based on the results and conclusions made from this study, HSC may be recommended in laying 
hens up to $30 \%$ to enhance the unsaturated fatty acid content in eggs, that may contribute to enhance human health.

\section{CONFLICT OF INTERESTS}

The authors have not declared any conflict of interests.

\section{REFERENCES}

Association of Official Analytical Chemists (AOAC) (1990). Official Methods of Analysis. 15th ed. AOAC Int., Washington, DC.https://law.resource.org/pub/us/cfr/ibr/002/aoac.methods.1.1990. pdf

Bovan Management and commercial Product Guide (2019). Amino acid and nutrient requirements for all layers at all ages; North American Version https://www.bovans.com/en/product/bovans-brown

Callaway JC (2004) Hempseed as a nutritional resource: An overview. Euphytica 140(1):65-72. https://doi.org/10.1007/s10681-004-4811-6 https://link.springer.com/article/10.1007/s10681-004-4811-6

Cherian G, Traber MG, Goeger MP, Leonard SW (2007). Conjugated Linoleic Acid and Fish Oil in Laying Hen Diets: Effects on Egg Fatty Acids, Thiobarbituric Acid Reactive Substances, and Tocopherols During Storage. Poultry Science 86(5):953-958 https://doi.org/10.1093/ps/86.5.953https://www.sciencedirect.com/sci ence/article/pii/S0032579119398773?via\%3Dihub

Darshan SK, Rudolph IL (2000). Effect of fatty acids of w-6 and w-3 type on human immune status and role of eicosanoids. Nutrition 16:143-145. DOI: 10.1016/S0899-9007(99)00256-7 https://www.sciencedirect.com/science/article/abs/pii/S08999007990 02567.

Erasmus U (1993). Fats that Heal, Fats that Kill, $3^{\text {rd }}$ edition. Alive Books, Burnaby, BC, Canada. https://www.worldcat.org/title/fats-that-healfats-that-kill-the-complete-guide-to-fats-oils-cholesterol-and-humanhealth/oclc/34967314

Folch J, Lees M, Stanley GHS (1957). A simple method for the isolation and purification of total lipid from animal tissues. Journal of Biology Chemistry 226(1):497-509. 13428781 https://www.semanticscholar.org/paper/A-simple-method-for-theisolation-and-purification-FolchLees/f030d83780d99235c565a9363ff1b3893b542aa5

Gakhar N, Goldberg E, Jing M, Gibson R, House JD (2012). Effect of feeding hemp seed and hemp seed oil on laying hen performance and egg yolk fatty acid content: evidence of their safety and efficacy for laying hen diets. Poultry Science 91(3):701-711. DOI: $10.3382 /$ ps.2011-01825

https://www.sciencedirect.com/science/article/pii/S003257911940234 4

Gonzalez-Esquerra R, Leeson S (2001). Alternatives for enrichment of eggs and chicken meat with omega-3 fatty acids. Can. Journal Animal Science 81(3):295-305. DOI: 10.4141/A00-092 https://www.researchgate.net/publication/269637804_Alternatives_for enrichment_of_eggs_and_chicken_meat_with_omega-3_fatty_acids

Halle I, Schone F (2013). Influence of rapeseed cake, linseed cake and HSC on laying performance of hens and fatty acid composition of egg yolk. Journal Fur Verbraucherschutz und Lebensmittelsicherheit (Journal of Consumer Protection and Food Safety) 8:185-193. DOI:10.1007/s00003-013-0822-3https://agris.fao.org/agrissearch/search.do;jsessionid=033144F3378002ADD8CA9A3C6DC91 1DB? request locale=es\&recordID=US201400132859\&sourceQuery= \&query=\&sortField=\&sortOrder=\&agrovocString=\&advQuery=\&center String $=$ \&enableField $=$

Health Canada (2012). List of Approved Cultivars for the 2012 Growing Season. Industrial Hemp Regulations Cannabis sativa, L. Accessed Sep. 2013. http://www.hc-sc.gc.ca/hc-ps/pubs/precurs/ list_cultivarsliste2012/index-eng.php.
House JD, Neufeld J, Leson G (2010). Evaluating the quality of protein from hemp seed (Cannabis sativa L.) products through the use of the protein digestibility-corrected amino acid score method. Journal of Agricultural Food Chemistry 58(22):11801-11807. DOI: $10.1021 / \mathrm{jf102636 \textrm {b }} \quad$ Available from: https://pubmed.ncbi.nlm.nih.gov/20977230

Jing M, Zhao S, Hous JD (2017). Performance and tissue fatty acid profile of broiler chickens and laying hens fed hemp oil and HempOmegaTM. Poultry Science 96(6):1809-1819. DOI: 10.3382/ps/pew476 https://pubmed.ncbi.nlm.nih.gov/28160006/

Kris-Etherton PM, Harris WS, Appel LJ (2003). Fish consumption, fish oil,omega-3 fatty acids, and cardiovascular disease. Arteriosclerosis Thrombosis Vascular Biology 23(2):e20-e30. PMID: 12588785 DOI: 10.1161/01.atv.0000038493.65177.94 https://pubmed.ncbi.nlm.nih.gov/12588785/

Kris-Etherton PM, Taylor DS, Yu-Poth S, Huth P, Moriarty K, Fishell VR, Hargrove L, Zhao G, Etherton TD (2000). Polyunsaturated fatty acids in the food chain in the United States. The American Journal Clinical Nutrition 71(1):S179-S188. PMID: 10617969 DOI: 10.1093/ajcn/71.1.179S https://pubmed.ncbi.nlm.nih.gov/10617969/

Lewis NM, Seburg S, Flanagan NL (2000). Enriched eggs as a source of N-3 polyunsaturated fatty acids for humans. Poultry Science 79(7):971-974. DOI: 10.1093/ps/79.7.971 https://pubmed.ncbi.nlm.nih.gov/10901195/

Lukas V, Frantisek B, Krmela A, Svobodova V, Hajsolva J, Mastovska K (2018). "Quantification of Cannabinoids in Cannabis Dried Plant Materials, Concentrates, and Oils Liquid Chromatography-Diode Array Detection Technique with Optional Mass Spectrometric Detection," First Action Method, Journal of AOAC International, Future Issue; Official Methods of Analysis, Method 2018.11, AOAC International (Modified). https://doi.org/10.1093/jaoac/102.6.1822 https://academic.oup.com/jaoac/article-abstract/102/6/1822/5658337

Malone T, Gomez K (2018). Hemp in the United States; A Case Study of Regulatory Path Dependency Applied Economic Perspectives and Policy 41(2):199-214. https://doi.org/10.1093/aepp/ppz001 https://onlinelibrary.wiley.com/doi/abs/10.1093/aepp/ppz001

March BE, MacMillan C (1990) Linoleic acid as a mediator of egg size. Poultry Science 69:634-639. https://doi.org/10.3382/ps.0690634 https://www.sciencedirect.com/science/article/pii/S003257911932752 $\mathrm{X}$

Mierliță D (2019). Fatty acids profile and oxidative stability of eggs from laying hens fed diets containing hemp seed or hempseed cake. South African Journal of Animal Science 49(2):310-321 DOI: 10.4314/sajas.v49i2.11 https://www.researchgate.net/publication/333364808_Fatty_acids_pr ofile_and_oxidative_stability_of_eggs_from_laying_hens_fed_diets_c ontaining hemp_seed_or_hempseed cake

Parker T, Adams D, Zhou K, Harris M, Yu L (2003). Fatty Acid Composition and Oxidative Stability of Cold-pressed Edible Seed Oils. Journal of Food Science 68(4):1240-1243. doi:10.1111/j.13652621.2003.tb09632.x

https://onlinelibrary.wiley.com/doi/abs/10.1111/j.13652621.2003.tb09632.x

Ribeiro T, Lordelo MM, Costa P, Alves SP, Benevides WS, Bessa, RJB, Lemos JPC, Pinto RMA, Ferreira LM, Fontes CM, Prates JA (2014). Effect of reduced dietary protein and supplementation with a docosahexaenoic acid product on broiler performance and meat quality. British Poultry Science 55(6):752-765. PMID: 25277689 DOI: 10.1080/00071668.2014.971222 https://pubmed.ncbi.nlm.nih.gov/25277689/

SAS (2012). SAS System for Microsoft Windows. Release 9.2.SAS Institute Inc., Cary, NC., USA.

Silversides FG, Lefrancois MR (2005). The effect of feeding hemp seed meal to laying hens. British Poultry Science 46(2):231-235. DOI: 10.1080/0071660500066183. https://www.researchgate.net/publication/7786291_Effect_of_feeding _hemp_seed_meal_to_laying_hens

Simopoulos AP (1994). Is insulin resistance influenced by dietary linoleic acid and trans fatty acids? Free Radiology Biology Medicine 17(4):367-72. 
Simopoulos AP (2002). The importance of the ratio of omega-6/omega3 essential fatty acids. Biomed Pharmacother 56(8):365-379 DOI: $10.1159 / 000073788$ www.elsevier.com/locate/biopha https://www.researchgate.net/publication/9038816_Importance_of_th e_Ratio_of_Omega-6 3_Essential_Fatty_Acids_Evolutionary_Aspects Omega-

Turner CE, Cheng PC, Lewis GS, Russel MH, Sharma GK (1979). Constituents of Cannabis sativa XV: Botanical and chemical profile of Indian variants. Planta Medicine 37:217-225. DOI: 10.1055/s-00281097331 https://www.thiemeconnect.com/products/ejournals/abstract/10.1055/s-0028-1097331 https://agris.fao.org/agrissearch/search.do?recordID=US201302110354

Weber PC (1989). Are we what we eat? Fatty acids in nutrition and in cell membranes: cell functions and disorders induced by dietary conditions. Fish fats and your health. Norway: Svanoy Foundation, 9:18.
Weber PC, Leaf A (1991). Cardiovascular effects of w3 fatty acids:atherosclerotic risk factor modification by w3 fatty acids. In: Simopoulos AP, Kifer RR, Martin RE, editors. Health Effects of w3polyunsaturated fatty acids in seafoods. World Review of Nutrition and Dietetics Karger 66:218-32. 